\title{
MACROZONING FOR EARTHQUAKE ENGINEERING
}

Deformation at the collision edges of two vast moving tectonic plates, the Pacific and the Australian, has created and is now modifying our country. Dunedin and Auckland owe their existence to this slow violence no less than do Christchurch and Wellington. That seismicity varies from place to place has been inferred from studies of land forms with some rough, possibly fortuitous, confirmation from the short historical record. No part of the country is safe, and for no part has there been any adequate study to quantify the risk. Nevertheless, this tiny sliver of 1 and has been: divided into five macrozones to which numbers have been at tached indicating very significant differences in intuitively selected seismic risk factors for design.

In no other seismically active area on earth where well developed seismic design rules are in force and where the distance from a great subduction zone is comparable is there such minute and significant subdivision into risk zones as in New Zealand. Thus Anchorage, Alaska, formerly considered to be an area of moderate intensity for design of most buildings, and hastily reassessed after the disaster of Good Friday, 1964, is further from its closest subduction zone than are any of New Zealand's major urban areas, and much of Japan is more remote than is Dunedin. These comparisons show how attitudes elsewhere differ from those prevailing here. They should persuade us to re-examine both the basis for macrozoning and the detail of the regulations.

Two levels of earthquake excitation are to be considered: one, a "design" earthquake which may be expected to occur at any place once within the lifetime of a structure, and $t w o, a$ "maximum credible" earthquake. Zoning on a frequency of occurrence basis should (if adequate data are available) be considered for the "design" earthquake. It is irrelevant for the "maximum credible" earthquake. This essential difference between the design treatment for the two cases is not recognised in our current zoning rules. In so far as "maximum credible" earthquake excitation nearly always controls main frame design, we should consider abandoning macrozoning concepts for the ultimate safety provisions in our rules, and retaining these concepts only for the secondary damage requirements. If this is politically unacceptable, our scheme for main frame design should be based on the Japanese model which specifies trivial and practically inconsequential differences between the zones.

Moreover, for the "design" earthquake we should carefully check those of our rules that are controlled by zoning to eliminate the manifestly irrational features that now apply.

\begin{abstract}
Contrary to the indications in our present pseudo spectra for design shear, low frequency disturbances suffer much less attenuation in their travel through the earth's crust than do high frequency disturbances. Thus flexible buildings can and do respond violently to distant earthquakes. A striking illustration of the susceptibility of high rise buildings to distant earthquakes was the recent vigorous response of such a building in Adelaide to excitation from a Timor earthquake with an epicentral distance of more than 2,000 miles. It would be foolish to ignore such warnings in the redrafting of our seismic design rules.
\end{abstract}

